\title{
Low Turn-on Voltage InGaP/GaAsSb/GaAs Double HBTs Grown by MOCVD
}

\author{
B. P. Yan, C. C. Hsu, X. Q. Wang, and E. S. Yang
}

\begin{abstract}
A novel InGaP/GaAs ${ }_{0.92} \mathrm{Sb}_{0.08} / \mathrm{GaAs}$ double heterojunction bipolar transistor (DHBT) with low turn-on voltage has been fabricated. The turn-on voltage of the DHBT is typically $150 \mathrm{mV}$ lower than that of the conventional InGaP/GaAs HBT, indicating that GaAsSb is a suitable base material for reducing the turn-on voltage of GaAs HBTs. A current gain of 50 has been obtained for the InGaP/GaAs ${ }_{0.92} \mathrm{Sb}_{0.08} / \mathrm{GaAs}$ DHBT. The results show that InGaP/GaAsSb/GaAs DHBTs have a great potential for reducing operating voltage and power dissipation.
\end{abstract}

Index Terms-DHBT, GaAs/GaAsSb/GaAs DHBT, GaAsSb, InGaP/GaAss ${ }_{0.92} \mathrm{Sb}_{0.8} / \mathrm{GaAs}$, low turn-on voltage, MOCVD.

\section{INTRODUCTION}

G aAs-BASED heterojunction bipolar transistors (HBTs) have been widely used in high-performance microwave and digital communication systems. However, they have a relatively large base-emitter turn-on voltage due to the large band gap of GaAs used as the base layer, and this limits the minimum operating voltage and increases the power consumption in circuit applications. For low voltage operation, InP-based HBTs are the most suitable candidate because they have a turn-on voltage of smaller than $0.5 \mathrm{~V}$. However, InP has disadvantages of brittleness, unavailability of large diameter wafers, and high substrate cost compared to GaAs. Therefore, it is important to develop novel GaAs-based HBTs with a narrow band gap base. For this reason, GaInAsN has lately attracted considerable attention as the base layer of GaAs HBTs [1]-[3]. By incorporating a proper amount of nitrogen and indium into GaAs, GaInAsN lattice-matched to GaAs can be obtained with a significant energy band-gap reduction. However, because of the large conduction-band discontinuity between InGaAsN base and GaAs collector, a collector current blocking effect would occur, giving rise to a drastic degradation of current gain at a high collector current density [1]. Although by the insertion of graded layers between the base and collector junction, the current blocking effect can be suppressed, this complicates the transistor design and fabrication.

\footnotetext{
Manuscript received November 6, 2001; revised December 20, 2001. This work was supported by a grant from the Research Grants Council of Hong Kong Special Administrative Region, Hong Kong (Project HKU 7057/98E) and by CRCG Grants 37/062/0047 and 10201982. The review of this letter was arranged by Editor D. Ritter.

B. P. Yan, X. Q. Wang, and E. S. Yang are with the Department of Electrical and Electronic Engineering, The University of Hong Kong, Hong Kong (e-mail: bpyan@eee.hku.hk).

C. C. Hsu is with the Department of Electrical and Electronic Engineering, The University of Hong Kong, Hong Kong, and also with the Department of Electronic Engineering, The Chinese University of Hong Kong, Hong Kong.

Publisher Item Identifier S 0741-3106(02)03211-1.
}

We focus on $\mathrm{GaAsSb}$ as the narrow band gap material for the base layer of GaAs HBTs. In comparison with a lattice-matched GaAs base, the smaller band gap of GaAsSb should reduce the turn-on voltage, thus the power dissipation in circuits. Moreover, the band lineup at the $\mathrm{GaAsSb} / \mathrm{GaAs}$ interface is staggered ("type II") lineup [4], which would eliminate any collector current blocking. Although GaAs-based HBTs with GaAsSb base layer have already been reported [5]-[8], their emitter-base junction was either an AlGaAs/GaAsSb [5]-[7] or a GaAs/GaAsSb heterojunction [8], and the devices showed poor dc current gain and large recombination current. In this work, we use GaAsSb as the base layer to reduce the turn-on voltage. At the same time, InGaP is used as the emitter to increase the valence band discontinuity and improve the current gain.

\section{Material Growth and Device Fabrication}

InGaP/GaAs ${ }_{0.92} \mathrm{Sb}_{0.08} / \mathrm{GaAs}$ DHBT structures were grown on a semi-insulating (100) GaAs substrate by MOCVD. Epitaxial growth was performed in a commercial (Aixtron) MOCVD system. Trimethylgallium, trimethylindium, trimethylantimony, tertiarybutylphosphine, and tertiarybutylarsine were used as the organometallic sources. Carbon and silicon were used as p- and n-type dopants. The device structure is shown in Table I. A standard InGaP/GaAs HBT structure from Kopin Corporation was used for comparison, which has a base thickness of $1000 \AA$ and a doping of $4 \times 10^{19} \mathrm{~cm}^{-3}$. GaAsSb is not lattice matched to GaAs, which limits how much $\mathrm{Sb}$ can be incorporated without forming dislocations. The Sb alloy composition of the base was chosen such that it would be close to this pseudomorphic limit at the thickness of the base layer. The $\mathrm{Sb}$ composition was confirmed by high-resolution $x$-ray diffraction measurement. The thickness of the $\mathrm{GaAs}_{0.92} \mathrm{Sb}_{0.8}$ base layer is $500 \AA$, which is in good agreement with published values for the critical layer thickness [6], [7]. We also observed the surface morphology by atomic force microscope (AFM) and no crosshatched patterns associated with misfit dislocations were observed. This suggests that the GaAsSb base layer is fully strained. Mesa structure devices were fabricated. Standard photolithography and chemical wet selective etching were used in the device processing. AuGe/Ni/Au was used as emitter electrode and an emitter mesa was formed by using the emitter metal as an etching mask. The base electrode is Ti/Pt/Au and collector metal is AuGe/Ni/Au. They were formed by lift-off processes and alloyed at $410{ }^{\circ} \mathrm{C}$ for $10 \mathrm{~s}$. The devices were mesa-isolated and did not receive any surface passivation treatment. 
TABLE I

MATERIAL STRUCTURE OF THE INGAP/GAAsSB/GAAs DHBT BY MOCVD

\begin{tabular}{ccccc}
\hline Layer name & Material & $\mathrm{x}$ & $\begin{array}{c}\text { Doping } \\
\left(\mathrm{cm}^{-3}\right)\end{array}$ & $\begin{array}{c}\text { Thickness } \\
(\AA)\end{array}$ \\
\hline Cap layer & $\mathrm{n}^{+}-\mathrm{In}_{\mathrm{x}} \mathrm{Ga}_{1-\mathrm{x}} \mathrm{As}$ & 0.5 & $>1 \times 10^{19}$ & 500 \\
Cap layer & $\mathrm{n}^{+}-\mathrm{In}_{\mathrm{x}} \mathrm{Ga}_{1-\mathrm{x}} \mathrm{As}$ & $0-0.5$ & $>1 \times 10^{19}$ & 500 \\
Cap layer & $\mathrm{n}^{+}-\mathrm{GaAs}$ & & $4 \times 10^{18}$ & 1500 \\
Emitter layer & $\mathrm{In}_{\mathrm{x}} \mathrm{Ga}_{1-\mathrm{x}} \mathrm{P}$ & 0.5 & $3 \times 10^{17}$ & 500 \\
Base & $\mathrm{p}^{+}-\mathrm{GaAs}_{1-\mathrm{x}} \mathrm{Sb}$ & & $2 \times 10^{19}$ & 500 \\
Collector & $\mathrm{n}^{-}-\mathrm{GaAs}$ & & $5 \times 10^{16}$ & 5000 \\
Sub-collector & $\mathrm{n}^{+}-\mathrm{GaAs}$ & & $3 \times 10^{18}$ & 5000 \\
S. I. GaAs & & & & \\
\hline
\end{tabular}



Fig. 1. Dependence of collector current density on emitter-base voltage $V_{\mathrm{bc}}$ of an InGaP/GaAs ${ }_{0.92} \mathrm{Sb}_{0.08} / \mathrm{GaAs} \mathrm{DHBT}$ and a conventional InGaP/GaAs HBT with an emitter size of $30 \times 40 \mu \mathrm{m}^{2}$.

\section{DeVICE PERformance AND Discussion}

The dc performances of the devices were measured using a HP4155 semiconductor parameter analyzer. Fig. 1 shows the dependence of the collector current density $J_{c}$ on the base-emitter voltage $V_{\text {be }}$ of an InGaP/GaAs ${ }_{0.92} \mathrm{Sb}_{0.08} / \mathrm{GaAs}$ DHBT and an standard InGaP/GaAs HBT with an same emitter size of $30 \times 40 \mu \mathrm{m}^{2}$. As shown in Fig. 1, the turn-on voltage $V_{\text {on }}$ of the InGaP/GaAs HBT at $J_{c}=1 \mathrm{~A} / \mathrm{cm}^{2}$ is $1.085 \mathrm{~V}$ and the $V_{\text {on }}$ of the DHBT is $0.935 \mathrm{~V}$. The $V_{\text {on }}$ of InGaP/GaAs $0.92 \mathrm{Sb}_{0.08} / \mathrm{GaAs}$ DHBT is $150 \mathrm{mV}$ lower than that of standard InGaP/GaAs HBT. In view of the influence of the changes in the base doping and the base thickness, which cause a reduction of $24 \mathrm{mV}$ according to the calculation method proposed by the literature [2], the real reduction of the turn-on voltage produced by increasing Sb composition in GaAs is 126 $\mathrm{mV}$. On the other hand, the reduction of the band gap and the valence band offset produced by increasing $\mathrm{Sb}$ composition in GaAs can be estimated by following expressions [4]:

$$
\begin{aligned}
& \Delta E_{g}\left(x_{\mathrm{Sb}}\right)=1.79 x_{\mathrm{Sb}}-1.54 x_{\mathrm{Sb}}^{2} \\
& \Delta E_{v}\left(x_{\mathrm{Sb}}\right)=1.97 x_{\mathrm{Sb}}-1.69 x_{\mathrm{Sb}}^{2}
\end{aligned}
$$

where $x_{\mathrm{Sb}}$ is the $\mathrm{Sb}$ composition in GaAsSb alloy, $\Delta E_{g}$ is the reduction of the band gap produced by increasing $\mathrm{Sb}$ composition in GaAs, and $\Delta E_{v}$ is produced valence band offset. The aforementioned expressions are based on the PL measurement

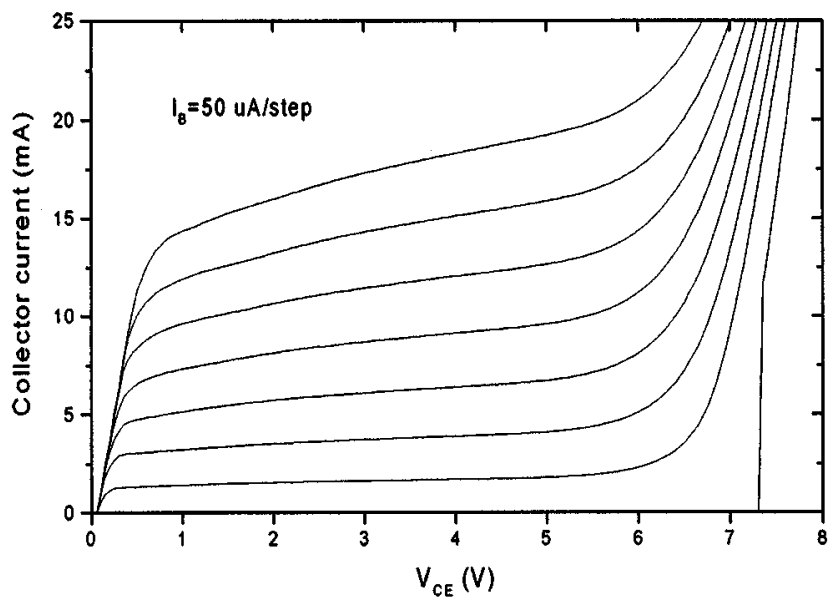

Fig. 2. Common-emitter $I-V$ characteristics of $\mathrm{InGaP} / \mathrm{GaAs}_{0.92} \mathrm{Sb}_{0.08}$ /GaAs DHBT with an emitter size of $30 \times 40 \mu \mathrm{m}^{2}$.

and theoretical calculation. From the expressions (1) and (2), we can obtain $\Delta E_{g}=133 \mathrm{meV}$ and $\Delta E_{v}=146 \mathrm{meV}$ for $8 \% \mathrm{Sb}$ composition, respectively. The reduction of the $V_{\text {on }}$ is in excellent agreement with the reduction $\left(\Delta E_{g}\right)$ of the band gap. The reduction of the $V_{\text {on }}$ is also almost consistent with the reduction $\left(\Delta E_{v}\right)$ of the estimated valence band offset. This indicates that the band gap offset produced by increasing $\mathrm{Sb}$ composition mainly appears on the valence band. In addition, it can be seen from Fig. 1 that the collector current begins to saturate for the GaAsSb base HBT near $10 \mathrm{~A} / \mathrm{cm}^{2}$, but not for the GaAs base HBT. This is due to the large base series resistance of the GaAsSb HBT, which comes from both low base doping (only $\sim 2 \times 10^{19} \mathrm{~cm}^{-3}$ ) and bad base ohmic contact. Measured base sheet resistance for the GaAsSb DHBT is $1986 \Omega / \square$ and the base specific contact resistance is about $1.5 \times 10^{-4} \Omega \cdot \mathrm{cm}^{2}$. In contrast, the base sheet resistance and the base specific contact resistance for the $\mathrm{InGaP} / \mathrm{GaAs}$ HBT are $182 \Omega / \square$ and $5.52 \times 10^{-7} \Omega \cdot \mathrm{cm}^{2}$, respectively. Fig. 2 shows the common emitter current-voltage $(I-V)$ characteristics of the DHBT. The device displays uniform current gain from low to high current level. The dc current gain is about 40 and the incremental current gain $H_{f e}$ is more than 50 at a collector current level of $I_{C}=10 \mathrm{~mA}$. Measured emitter-collector offset voltage is $59 \mathrm{mV}$ and the breakdown voltage of emitter-collector $\mathrm{BV}_{\mathrm{ceo}}$ is $6-7 \mathrm{~V}$. The device shows a lower Early voltage. It may be related to the blocking spike forming in the conduction band on the collector side of the base, due to inadequate grading distance for the Sb. Further experimental study is under way. Fig. 3 shows representative Gummel plots for the InGaP/GaAs ${ }_{0.92} \mathrm{Sb}_{0.08} / \mathrm{GaAs}$ DHBT. The ideality factor of the collector current is 1.00 and that of the base current is 1.12 . The low base current ideality factor indicates that little recombination takes place in the emitter-base space charge region [9]. It is worth noticing that there is still a current gain even at a collector current of $10^{-10} \mathrm{~A}$, which is probably due to the lower surface recombination of $\mathrm{InGaP}$ and the large valence band discontinuity at the $\mathrm{InGaP} / \mathrm{GaAsSb}$ interface. We obtained the identical current gains and ideality factors from a small device with an emitter area of $3 \times 8 \mu \mathrm{m}^{2}$. This observation suggests that the present DHBTs do not 


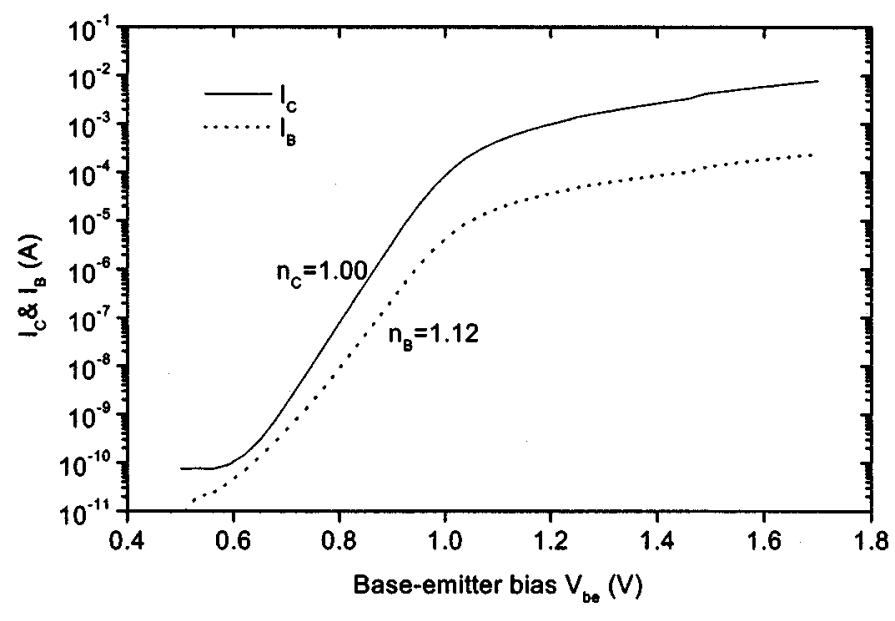

Fig. 3. Representative Gummel plots for $\mathrm{InGaP}_{\mathrm{GaAs}} \mathrm{G.92}_{2} \mathrm{Sb}_{0.08} / \mathrm{GaAs}$ DHBT with an emitter size of $30 \times 40 \mu \mathrm{m}^{2}$.

exhibit emitter size effect. The high gain down to low current densities can be used to minimize the power dissipation in circuit applications. In comparison with $\mathrm{GaAs} / \mathrm{GaAsSb} / \mathrm{GaAs}$ DHBT, where the current gain of 20 and the base current ideality factor of 2 were reported [8], the base recombination current of $\mathrm{InGaP} / \mathrm{GaAs}_{0.92} \mathrm{Sb}_{0.08} / \mathrm{GaAs} \mathrm{DHBT}$ is greatly reduced due to the use of $\mathrm{InGaP}$ as emitter layer. In addition to the improvement of the current gain, the use of InGaP emitter layer is also beneficial to the device reliability [10].

\section{CONCLUSION}

In summary, we have demonstrated the first InGaP $/ \mathrm{GaAs}_{0.92}$ $\mathrm{Sb}_{0.08} / \mathrm{GaAs}$ DHBT, which exhibits excellent DC performances. The device shows a low turn-on voltage, which is $150 \mathrm{mV}$ lower than that of conventional InGaP/GaAs HBTs. From the point of view of practical applications, a reduction of $0.4-0.5 \mathrm{~V}$ is required. This work provides a guideline to the reduction of the turn-on voltage. It shows that GaAsSb is a suitable base material for reducing the turn-on voltage of GaAs HBTs and the InGaP/GaAsSb/GaAs DHBTs can be a better candidate for the low turn-on voltage device. Our results also reveal that the In $\mathrm{GaP} / \mathrm{GaAsSb} / \mathrm{GaAs}$ DHBT grown by MOCVD is better than the GaAs/GaAsSb/GaAs DHBT grown by MBE.

\section{ACKNOWLEDGMENT}

The authors wish to thank Dr. W. Y. Cheung, Dr. N. Ke, Mr. E. K. C. Chan, and Mr. A. F. L. Ng for their technical assistance.

\section{REFERENCES}

[1] N. Y. Li, P. C. Chang, A. G. Baca, X. M. Xie, P. R. Sharps, and H. Q. Hou, "DC characteristics of MOVPE-grown Npn InGaP/InGaAsN DHBT," Electron. Lett., vol. 36, pp. 81-83, 2000.

[2] R. E. Welser, P. M. DeLuca, and N. Pan, "Turn-on voltage investigation of GaAs-based bipolar transistors with $\mathrm{Ga}_{1-x} \mathrm{In}_{x} \mathrm{As}_{1-y} \mathrm{~N}_{y}$ base layers," IEEE Electron Device Lett., vol. 21, pp. 554-556, 2000.

[3] H. Xin, C. W. Tu, P. M. Asbeck, and R. Welty, "Investigation of p-type GaInNAs for heterojunction bipolar transistor base layers," in Proc. Electronics Materials Conf., Santa Barbara, CA, 1999, p. 13.

[4] R. Teissier, D. Sicault, J. C. Harmand, G. Ungaro, G. Le Roux, and L. Largeau, "Temperature-dependent valence band offset and band-gap energies of pseudomorphic GaAsSb on GaAs," J. Appl. Phys., vol. 89, pp. 5473-5477, 2001.

[5] B. Khamsehpour and K. E. Singer, "GaAs-GaAsSb based heterojunction bipolar transistors,” Electron. Lett., vol. 26, pp. 965-967, 1990.

[6] K. Ikossi-Anastasiou, A. Ezis, K. R. Evans, and C. E. Stutz, "Double heterojunction bipolar transistor in $\mathrm{Al}_{x} \mathrm{Ga}_{1-x} \mathrm{As} / \mathrm{GaAs}_{1-y} \mathrm{Sb}_{y}$ system," Electron. Lett., vol. 27, pp. 142-144, 1991.

[7] K. Ikossi-Anastasiou, "GaAsSb for heterojunction bipolar transistors," IEEE Trans. Electron Devices, vol. 40, pp. 878-884, 1993.

[8] T. Oka, T. Mishima, and M. Kudo, "Low turn-on voltage GaAs heterojunction bipolar transistors with a pseudomorphic GaAsSb base," Appl. Phys. Lett., vol. 78, pp. 483-485, 2001.

[9] W. Liu, "Experimental comparison of base recombination currents in abrupt and graded $\mathrm{AlGaAs} / \mathrm{GaAs}$ heterojunction bipolar transistors," Electron. Lett., vol. 27, pp. 2115-2116, 1991.

[10] T. Takahashi, S. Sasa, A. Kawano, T. Iwai, and T. Fujii, "High reliability InGaP/GaAs HBT fabricated by self-aligned process," in IEDM Tech. Dig., 1994, pp. 191-194. 